\title{
Effectiveness of collective treatments in the prevention and treatment of bovine digital dermatitis lesions: A systematic review
}

\author{
Juan M. Ariza, ${ }^{*}{ }^{1}$ Anne Relun, ${ }^{*}$ Nathalie Bareille, ${ }^{*}$ Kenny Oberle, $\dagger$ and Raphaël Guatteo* \\ *BIOEPAR, INRA, Oniris, La Chantrerie, 44307 Nantes, France \\ †Qalian, Neovia, Segré 49500, France
}

\begin{abstract}
The collective treatment (CT) of an affected herd is commonly advised to control bovine digital dermatitis (DD). Several CT are commercialized, frequently without major evidence supporting their effectiveness. The objective of this systematic review was to evaluate the published evidence that supports $\mathrm{CT}$ in the treatment and prevention of DD lesions in dairy herds. Across the evidence, the main limitations in the studies design were identified and the possible sources of inconsistency were investigated. An extensive literature search of publications through electronic databases and gray literature was conducted between July 2015 and January 2016. Studies that did not include an untreated or placebo control group were excluded from the review. The literature search and screening process identified 13 publications with 24 treatment trial comparisons and 18 prevention trial comparisons. The published evidence included studies mostly considered to have a low or unclear risk of bias. Descriptive analyses were performed according to the prevention and treatment outcomes, and case and success definitions were identified for each study and summarized in odds ratios (OR). Pairwise meta-analyses were conducted according to the prevention and treatment outcomes, comparing directly the intervention used in each study, and ignoring any other differences in the intervention characteristics. The results of the meta-analyses indicated a low degree of heterogeneity across the evidence for the prevention outcome $\left[I^{2}=0 \%, 95 \%\right.$ CI: 0 to $37.2 \%, 95 \%$ prediction interval (PI): 0.72 to 1.74 )] and a moderate degree for the treatment outcome $\left(I^{2}=\right.$ $25.3 \%, 95 \%$ CI: 0 to $63 \%, 95 \%$ PI: 0.39 to 3.73). Similarly, appraisal of the graphical L'Abbé plot suggested a considerable degree of heterogeneity across the evidence for the treatment outcome. For both outcomes, the frequent small sample sizes of the trials indicate
\end{abstract}

Received August 16, 2016.

Accepted May 12, 2017.

${ }^{1}$ Corresponding author: juan-manuel.ariza@oniris-nantes.fr imprecision across the included studies. Additionally, for the treatment and prevention outcomes, an asymmetric funnel plot suggested possible publication bias. The overall quality of the evidence, for both outcomes (prevention and treatment), was therefore considered to be low, indicating that the true effect of CT may be substantially different from that estimated across the included studies. Consequently, this review and metaanalysis does not support an association between the $\mathrm{CT}$ considered in the review and a beneficial effect in the prevention and treatment of DD lesions. The effectiveness of CT therefore remains uncertain, and the epidemiological circumstances in which it can be useful must be investigated. These findings highlight the importance of developing high quality, controlled trials to evaluate the effectiveness of CT for DD control.

Key words: dairy cow, bovine digital dermatitis, collective treatment, meta-analysis, systematic review

\section{INTRODUCTION}

Bovine digital dermatitis (DD) is a multifactorial contagious disease, with worldwide distribution, characterized by painful and ulcerative lesions in the foot skin (Laven and Logue, 2006; Gomez et al., 2012). This condition is often associated with animal welfare concerns such as lameness (Bruijnis et al., 2012). Digital dermatitis is also related to economic issues such as reduced milk production, impaired reproductive performance, and increased risk of culling (Bruijnis et al., 2010; Ettema et al., 2010; Relun et al., 2013c). The disease affects 70 to $96 \%$ of dairy herds in Western Europe and North America, and the within-herd prevalence ranges from 5 to $30 \%$ among lactating cows (Brown et al., 2000; Holzhauer et al., 2006b; Cramer et al., 2008).

Despite more than 40 yr of research, the precise pathogenesis of the disease remains unclear. Nevertheless, the presence of specific Treponema species on feet suffering from cutaneous maceration is recognized as a major etiological component involved in the development of the disease (Gomez et al., 2012). Current control strategies aim to control the main risk factors of 
DD, such as moist and unhygienic conditions, to limit the spread of the infection. (Palmer et al., 2013; Relun et al., 2013c). These strategies rely particularly on the complementary use of individual medical topical treatment of active lesions and metaphylactic collective treatments (CT) of the entire affected herd. However, both approaches are time-consuming practices, presenting economic and environmental challenges for farmers and the veterinary industry (Relun et al., 2013b). Although antibiotics such as oxytetracycline and lincomycin are mainly used as individual treatments and their topical administration is considered effective (Apley, 2015), high rates of lesions recurrence $(50 \%)$ are reported for some of these products (Berry et al., 2012). The use of antibiotics furthermore should be limited in order to decrease antimicrobial resistance and withdrawal periods for milk. Moreover, the collective administration of antibiotics is no longer advised and such practices are already banned by European Union policies.

Disinfectants such as formaldehyde and copper sulfate $\left(\mathrm{CuSO}_{4}\right)$ have been used in footbaths as the standard $\mathrm{CT}$ in the control of DD. However, formaldehyde is carcinogenic and $\mathrm{CuSO}_{4}$ is toxic for the environment via accumulation in the soil (Ippolito et al., 2010). Moreover, a recent systematic review revealed that the effectiveness of $\mathrm{CuSO}_{4}$ footbaths against DD is not adequately supported by the evidence (Thomsen, 2015). In addition, new evidence suggests possible genetic resistance to copper and zinc in microbiomes associated with DD lesions (Zinicola et al., 2015). Currently, several CT for DD are commercially available, most of which are supported by anecdotal evidence and a few by clinical trials (Laven and Logue, 2006). However, high variability in the efficacy of some of the products evaluated by scientific studies is perceived in practice (Relun et al., 2013b). Last, for most CT, their bactericidal efficacy against DD Treponema groups remains uncertain (Hartshorn et al., 2013).

In evidence-based veterinary medicine, randomized controlled trials (RCT) are considered the gold standard to guide treatment and prevention decisions. However, under certain circumstances, such as on commercial dairy farms, it can be difficult to conduct RCT for practical reasons. Consequently, part of the existing evidence about CT is based on non-randomized studies (Sargeant et al., 2014). The results of scientific studies on DD are furthermore often difficult to extrapolate to real conditions; this is most likely due to a lack of guidelines for CT use under diverse conditions (Relun et al., 2013b).

An assessment summarizing the scientific evidence concerning existing CT based on an objective procedure is therefore required to assist veterinarians and farmers in their DD control decisions. The main objective of the present systematic review was to evaluate the evidence supporting the use of $\mathrm{CT}$ in the treatment and prevention of DD to provide new insights into the design of high-quality DD control effectiveness trials. Data from multiple studies were combined through a meta-analysis to investigate the main sources of heterogeneity between studies and to calculate a summary effect estimate of the effectiveness of $\mathrm{CT}$ in the treatment and prevention of DD.

\section{MATERIALS AND METHODS}

The review was conducted following the guidelines proposed by Sargeant and O'Connor (2014) for systematic reviews in animal agriculture and veterinary medicine. A protocol was developed a priori that included a detailed description of the review process (Supplemental Data File S1; https://doi.org/10.3168/ jds.2016-11875).

\section{Search Strategy}

The review questions were designed based on the evidence-based veterinary medicine concept of PICO terms: population $(\mathrm{P})$, intervention $(\mathrm{I})$, comparator $(\mathrm{C})$, and outcomes (O) (Richardson et al., 1995). The study population of interest consisted of dairy cows, including heifers and lactating and dry cows. The intervention was CT, defined as the topical administration on feet of the same treatment (dose and frequencies) at a given time to 2 or more animals without restraining them individually. The comparators were parallel control groups of untreated animals (absence of CT) or groups treated with a water placebo. Two outcomes of interest were defined. The first involved prevention, where the outcome was the incidence, defined as the occurrence of new clinical DD lesions within the follow-up period. The second involved treatment, where the outcome was the healing of DD lesions, defined as the reduction of existent clinical DD lesions within the follow-up period. For both outcomes, the diagnosis and evolution of clinical lesions must be assessed by direct visual diagnosis and measured by an objective methodology (lesion score system). Two clinical questions were therefore defined as follows: "In dairy cows, are collective treatments more effective at preventing the occurrence of clinical lesions of bovine digital dermatitis compared to a placebo or the absence of any collective treatment?" and, "In dairy cows, are collective treatments more effective for the treatment of clinical lesions of bovine digital dermatitis compared to a placebo or the absence of any collective treatment?" 
Separate database searches were conducted for both outcomes simultaneously across PubMed, CAB, and Web of Science (core collection) between July 2015 and January 2016. The research was restricted to papers published between 1974 (first official description of DD) and 2016. No language restrictions were fixed. The citations, title, and abstract were screened for relevance by the principal author.

PubMed database searches were conducted using the Medical Subject Headings (MeSH) terminology and Boolean operators in this order: Cattle, Foot Diseases/ veterinary OR Digital Dermatitis/drug therapy OR Digital Dermatitis/prevention and control OR Digital Dermatitis/therapy AND Disinfectants/administration and dosage OR Disinfectants/therapeutic use OR AntiBacterial Agents/therapeutic use OR Copper Sulfate/ therapeutic use OR Anti-Infective Agents, Local OR Copper/therapeutic use OR Probiotics/therapeutic use OR Zinc/therapeutic use OR baths/veterinary"[Mesh] OR Occlusive Dressings/veterinary OR Administration, Topical Foot Diseases/veterinary OR Digital Dermatitis/drug therapy OR Digital Dermatitis/prevention and control OR Digital Dermatitis/therapy. Additionally, a manual search of the gray literature was performed by the principal author on the principal proceedings on the subject: World Buiatrics Congress 2002-2014, International Conference on Lameness in Ruminants 2002-2013, Cattle Lameness Conference 2009-2015, European Buiatrics Forum 2009-2013, the Journées 3R (Rencontres autour des recherches sur les ruminants) 1994-2015, and the British Society of Animal Science Conference 1999-2015.

For the relevant citations identified, their title, abstract, and materials and methods were verified for eligibility by 2 of the authors, who worked independently using a screening tool designed for this systematic review. Studies were eligible for the synthesis if a positive answer was given to all 4 of the following questions:

(1) Does the study describe a primary research study?

(2) Does the study evaluate CT in dairy herds?

(3) Does the study include the visual and objective measure of the incidence (prevention) or healing (treatment) of DD lesion, or both, as an outcome?

(4) Does the study include a parallel untreated control (absence of any CT) or a placebo group (water)?

In case of discrepancy between the 2 authors concerned, a third reviewer resolved the conflict.

\section{Data Collection Process}

The information considered as relevant to extract for this review was determined by the research team with the advice and supervision of a statistician involved in the study (Supplemental Data File S2; https://doi. org/10.3168/jds.2016-11875). Information was extracted by the principal author; in cases where the study data seemed confused or inconsistent, the assistance of the review team was requested.

The relevant information from each study trial was extracted at 5 levels (publication, population, intervention, outcome, and study design). The publication level includes author information, citation details, year of publication, and publication source (i.e., databases or gray literature). The population level includes data relative to the breed and lactation stage of the cows, the housing and milking system, and the initial prevalence of the disease in the herd. At the intervention level, information was extracted about the products used in the experimental and comparison groups, the type of intervention used (i.e., footbath, split footbath, foam system, collective spraying), the doses and frequencies of administration and, when appropriate, the concomitant individual treatments used. The data extracted at the outcome level included information about the number of outcome events by group as a rate derived from the $2 \times 2$ contingency tables, the frequency by which the measurements were taken, the follow-up time (from the first to last observation), the diagnostic methodologies used, and the "outcome unit" assessed (foot, cow). For each study, case and success definitions of DD clinical lesions were identified according to the treatment and prevention outcomes measured. For 2 studies, results were time-to-event outcomes (Relun et al., 2012, 2013a). In those cases, the proportions of outcome events in the intervention and control groups were provided by the authors. In one study (Thomsen et al., 2008), the proportions of outcome events and the OR (95\% CI) were combined for the overall intervention groups, because information about the number of events and subjects for each of the 3 intervention groups was unavailable.

Finally, at the study design level, information was extracted about randomization efforts, blinding of caregivers and observers, statistical methods used for analyses of the outcomes, handling of missing data, and the funding sources of the study. After the full-text assessment of the publication, the authors were contacted when some information was unavailable in the published paper.

The extracted data describing the effectiveness of the intervention were used to calculate the OR from the 
event proportions (incidence or healing) between the CT group and control group.

\section{Risk of Bias Assessment}

The quality of the evidence included was assessed independently by 2 reviewers using a "Risk of bias tool" created for this study and based on the recommendations of the "Cochrane collaboration's tool" for assessing the risk of bias in RCT (Higgins et al., 2011).

At the study level, sources of bias were evaluated in 5 domains (selection, performance, detection, attrition, and other bias). The selection bias domain assesses the efforts implemented in the trials to randomize the subjects or to balance the baseline risk among the intervention groups. The performance bias domain considers the measures used to reduce the effects linked to possible over usage of co-interventions or overprotection of animals in trials when the participants (caregivers) were aware about the group allocation. The detection bias domain assesses the methods and the objectivity by which the clinical evolution of DD lesions was measured (lesion score system). The attrition bias domain considers the amount, nature, and handling of incomplete outcome data. Finally, the "other bias" domain considers the possible carryover effects in the trials. After describing each bias domain, a grade of high, low, or unclear risk of material bias for each domain was assigned. Unclear risk was considered when the information relative to a domain was insufficient and when the possible risk of bias had an unknown effect.

From these within-study assessments, a general appreciation of the quality of each study was summarized in 3 categories: low risk of bias in studies with at least 4 domains judged as low; unclear risk of bias in studies with all key domains judged between low and unclear; and high risk of bias was considered in studies that judged one or more key domains as high.

The "risk of bias tool" used in this systematic review was modified from the one planned in the protocol in an effort to broadly approach the main methodological bias present in DD trials.

\section{Synthesizing the Overall Results}

The analyses were performed using the "meta" package in R (Schwarzer, 2015; R Core Team, 2015). For each trial and outcome evaluated (prevention or treatment), the number of events were entered for both the untreated or placebo control group and the experimental intervention group. We ignored any differences in intervention type, dose, or duration of therapy and directly compared the intervention group to the un- treated or placebo group in 2 different pairwise metaanalyses, one for the prevention and one for the healing of DD lesions. The publications where the data required for the quantitative synthesis were missing (e.g., number of events and subjects in the intervention and control groups) were excluded from the meta-analyses. Studies with multiple intervention group comparisons were combined to create single pairwise comparisons according to the type of $\mathrm{CT}$ application (i.e., spray and footbath). Therefore, in such cases, and according to the number of intervention groups formed, the control or placebo group was split into 2 or more comparisons (Higgins and Green, 2011). For the studies that reported multiple-outcomes observations during the follow-up period (Speijers et al., 2010; Relun et al., 2012, 2013a), only the data from the last observation session was included in the meta-analyses. The meta-analyses were performed by computing the study effect sizes in log OR and their 95\% CI, using a random effects model (DerSimonian and Laird method, DL; DerSimonian and Laird, 1986), assuming that the intervention effects varied across the trials following a normal distribution. The individual study OR were weighted by the inverse variance, so large studies provided more information to the summary OR. However, in trials where "outcome units" were clustered by herd or by cow side (right or left) in the herd, effective sample sizes were adjusted by the intracluster (or intraclass) correlation coefficient (ICC; mean 0.3) obtained from previous DD scientific studies (Holzhauer et al., 2006a; Cramer et al., 2008). Forest plots were created, including the OR and the summary effect calculated and their 95\% CI, with the size of the shaded box reflecting the relative contribution of each study to the summary OR.

Heterogeneity among studies was assessed using the L'Abbé plot, a graphical method that displays the relationship between baseline risk (baseline incidence rates and spontaneous healing rates) and intervention effectiveness across the trials (L'Abbé et al., 1987). On the graph, trials were plotted according to the beneficial superiority on the comparison of event proportions between the CT group and the control group, with point size being proportional to the size of the trial. The trials in which the beneficial effect was superior in the CT intervention group than in the control group were plotted between the y-axis and the line of equality. Those trials in which the beneficial effect was superior in the control group than in the CT intervention group were plotted between the x-axis and the line of equality. The locations of the different points or cluster formations in the graph were indicative of the level of agreement among trials. The Cochran's Q test was used to assess whether the variation in effect estimates were beyond 
chance. Between-study heterogeneity was quantified by the Higgins statistic $\left(I^{2}\right)$ with $95 \%$ CI and the tau squared $\left(\tau^{2}\right)$ calculation (Higgins and Thompson, 2002). Finally, to illustrate the amount of heterogeneity, the 95\% prediction intervals $(\mathbf{9 5 \%} \mathbf{P I})$ for the summary effects were calculated (Borenstein et al., 2017).

The small study effects, which may be caused by publication bias, were investigated using funnel plots, evaluating their symmetry both visually and objectively with Harbord's test (Higgins and Green, 2011).

Finally, subgroup analyses, determined a priori, to investigate possible sources of heterogeneity were conducted for study design (RCT vs. any other design), initial prevalence (high prevalence $>30 \%$ vs. low prevalence $<30 \%$ ), length of the study ( $>8$ wk vs. up to $8 \mathrm{wk}$ ) and follow-up assessments (before and after vs. multiple assessments). Post hoc subgroup analysis only included "study limitations" (low risk of bias vs. unclear/high risk of bias). The conditions for subgroup analyses were slightly changed from the protocol to enhance group formation and then allow the statistical comparisons. The threshold values for comparison were changed for initial prevalence (from 15 to $30 \%$ ) and for length of the study (from 12 to 8 wk).

\section{RESULTS}

\section{Search Results and Study Selection}

PubMed, CAB, and Web of Science databases searches yielded 65,233 , and 112 citations, respectively; 134 duplicates were removed. Six additional relevant publications were identified by manual searches. Taken together, 282 unique records were assessed for relevance

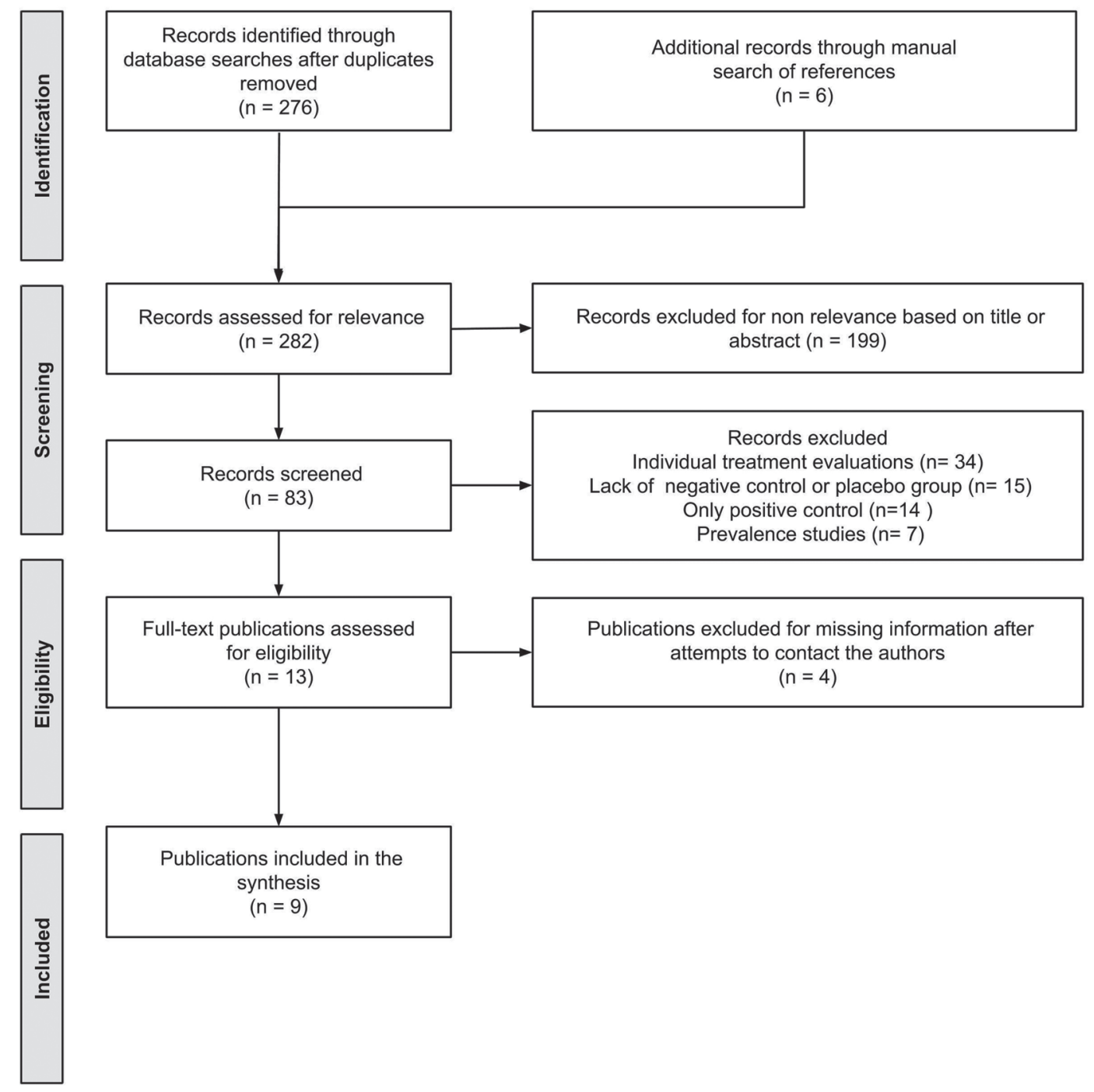

Figure 1. Summary of the search and selection process used to identify publications included in the systematic review. 
ARIZA ET AL.

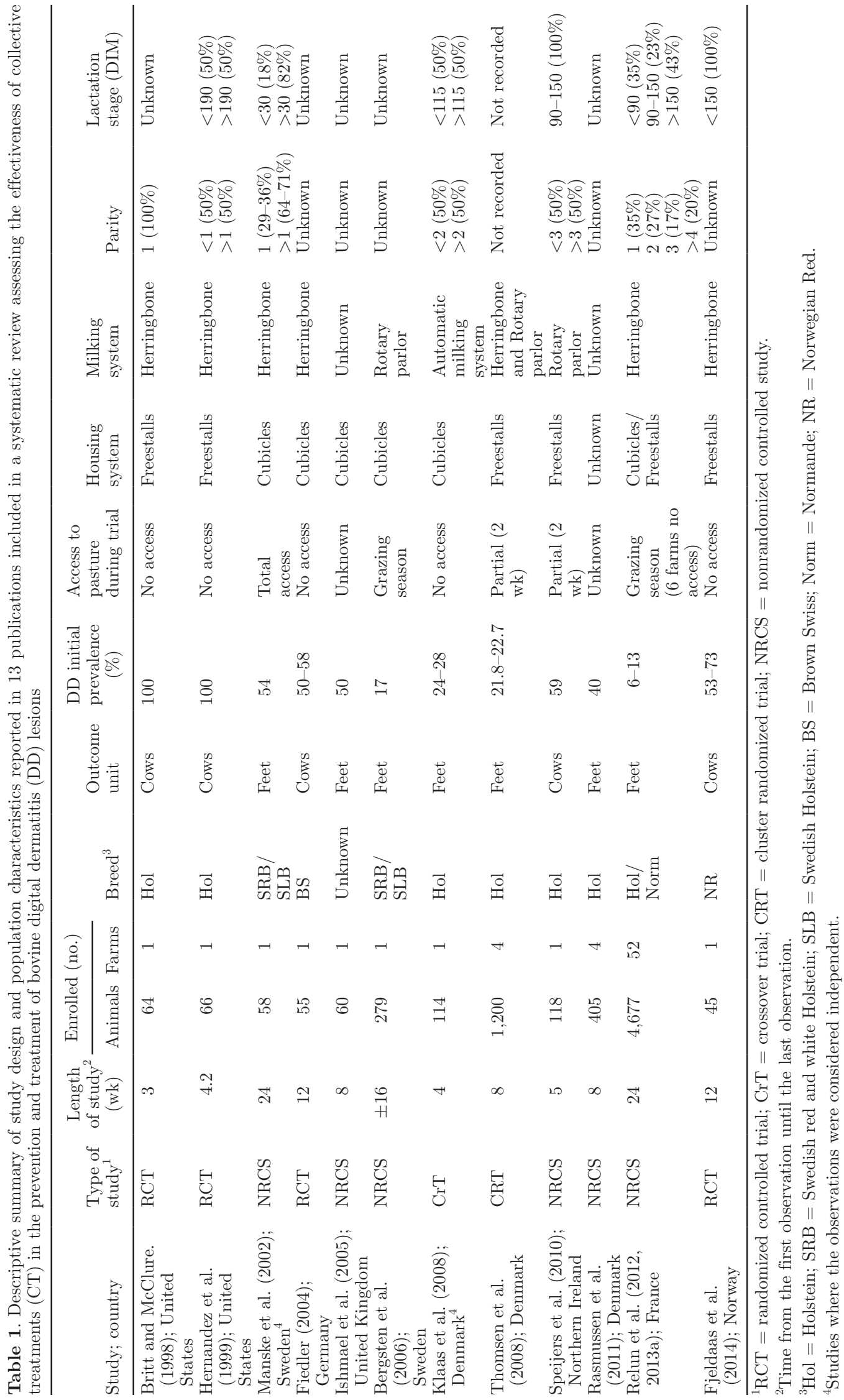


and, based on the title or abstract, 199 were excluded. Of the 83 relevant citations included for verification through the screening tool (title, abstract, and material and methods), 34 publications concerned evaluations of individual treatments, 29 publications lacked a comparative untreated or placebo control group, and 7 were observational prevalence studies. No discrepancies between the 2 reviewers were evidenced when using the screening tool. The full text of the remaining 13 publications was assessed through data extraction. After different attempts to contact the authors in cases of missing information, 4 additional publications were excluded and, finally, 9 papers were included in the quantitative synthesis (Figure 1).

\section{Study Characteristics}

Table 1 summarizes the main characteristics of the 13 relevant publications included in the systematic review. Five of the publications were retrieved from the gray literature and 8 from peer-reviewed journals. The year of publication ranged from 1998 to 2014. The majority of studies were undertaken in Europe, with only 2 in the United States. Six studies were RCT, including 1 crossover trial (CrT) and 1 cluster randomized trial (CRT). Six were nonrandomized controlled studies (NRCS), where subjects were allocated to interventions by nonrandomization methods. Before the start of the trials, initial DD prevalences ranged from 6 to 100\% among the studies. The length of the studies (period of CT administration and follow-up) ranged from 2 to $24 \mathrm{wk}$. Only 4 studies performed multiple-outcomes observations during the follow-up period (Ishmael et al., 2005; Speijers et al., 2010; Relun et al., 2012, 2013a). The preventive crossover trial included in the review (Klaas et al., 2008) did not have a washout period; therefore, only information on the first period of this study was considered for each group of animals as a trial. Among the 13 publications included in the systematic review, 9 trials evaluated the preventive outcome assessing 18 comparisons, and 11 trials evaluated the treatment outcome assessing 24 comparisons. Nine of the publications used untreated control groups and 4 used water placebos as control groups.

The quality assessments are displayed in Figure 2 . Within-studies assessments considered 5 studies to be at low risk of bias. Among them, unclear limitations were found in the selection and attrition bias domains. The remaining studies were considered to be at unclear (6) and high (2) risks of bias. In general, limitations were mostly related to randomization efforts (selection bias domain) and carryover effects (other bias domain), followed by the unclear risk of bias related to the studies' limitations in the handling of missing data (attrition bias domain) and the blinding of caregivers (performance bias domain).

Case and success definitions, proportions of outcome events (occurrence rates and healing rates), and the OR (95\% CI) associated with each study are reported in Tables 2 and 3, according to the prevention or treatment outcomes. For 4 studies, data on the results of the trials' effectiveness were unclear in the publication, and it was therefore impossible to calculate the proportion of outcome events and the OR (Fiedler, 2004; Ishmael et al., 2005; Bergsten et al., 2006; Rasmussen et al., 2011). Among the prevention trial comparisons, 17 products were tested involving different disinfectants; 9 of these relied on copper bactericidal properties, 2 on glutaraldehyde, 2 on organic acids, 1 on sodium hypochlorite, 1 on $\mathrm{NaCl}, 1$ on quaternary ammonium, and 1 on calcium hydroxide. Additionally, 2 prevention trial comparisons used water as the active CT. For the treatment outcome comparisons, 19 products were tested, with 9 based on copper, 4 on hydrogen peroxide, 2 on glutaraldehyde, and 1 on sodium hypochlorite. Two trials used water as the active treatment. Finally, an antibiotic was administered as a CT in only 2 studies, involving 2 treatment comparisons and 1 prevention comparison. The types of intervention used among the studies varied between footbath (7), spraying (4), foam

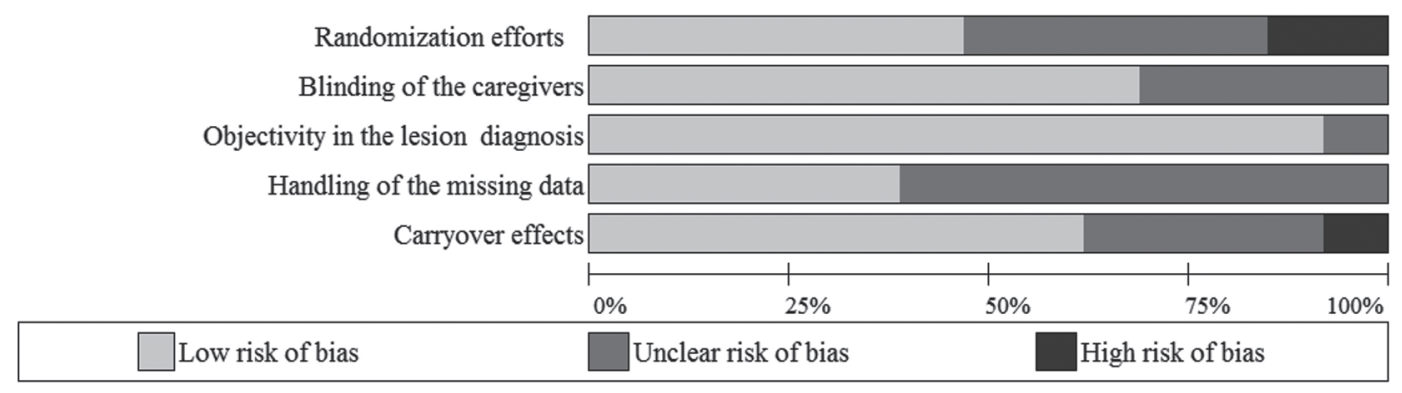

Figure 2. Graphical representation of the quality of the included studies, based on the risk of bias assessments. 


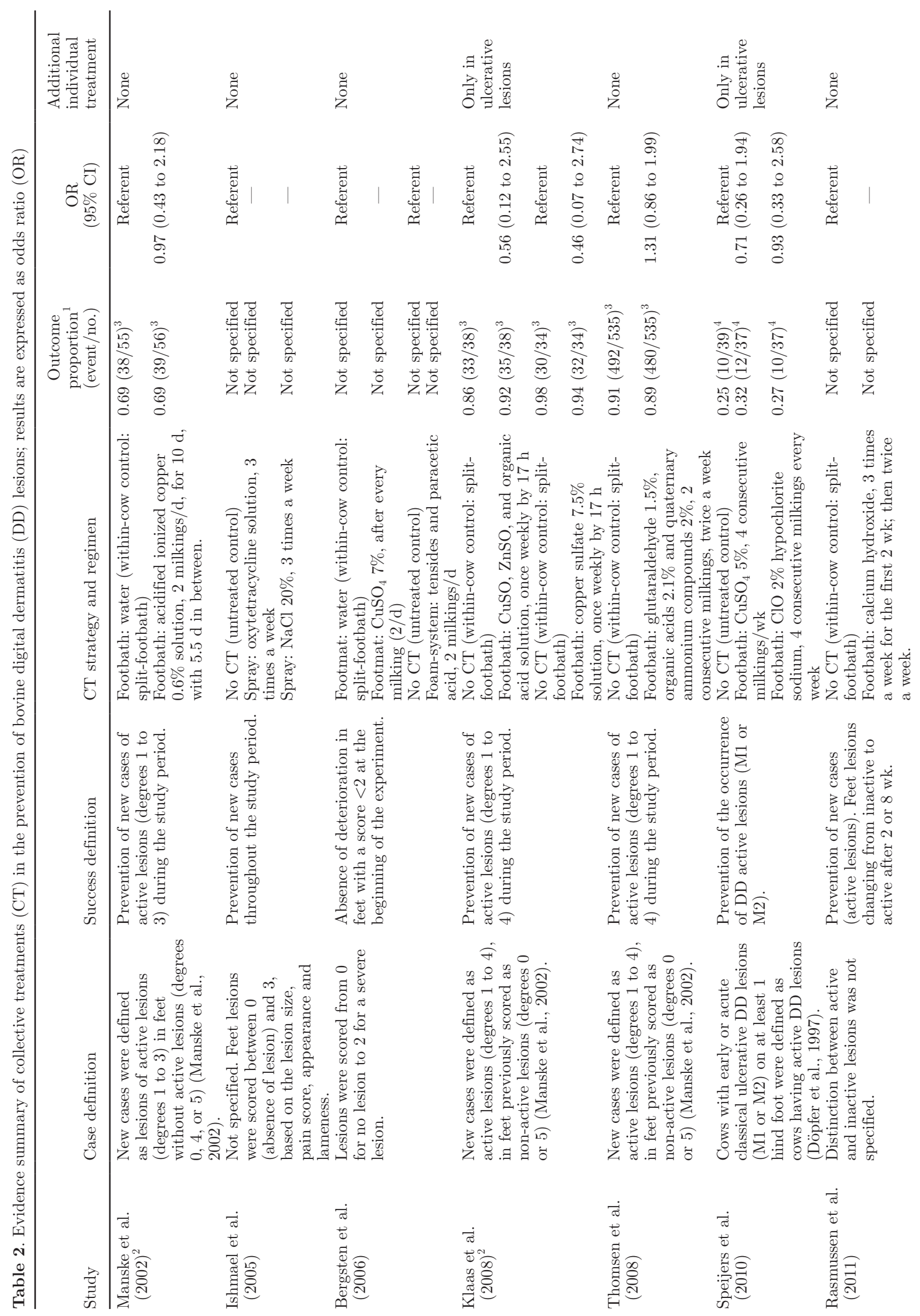




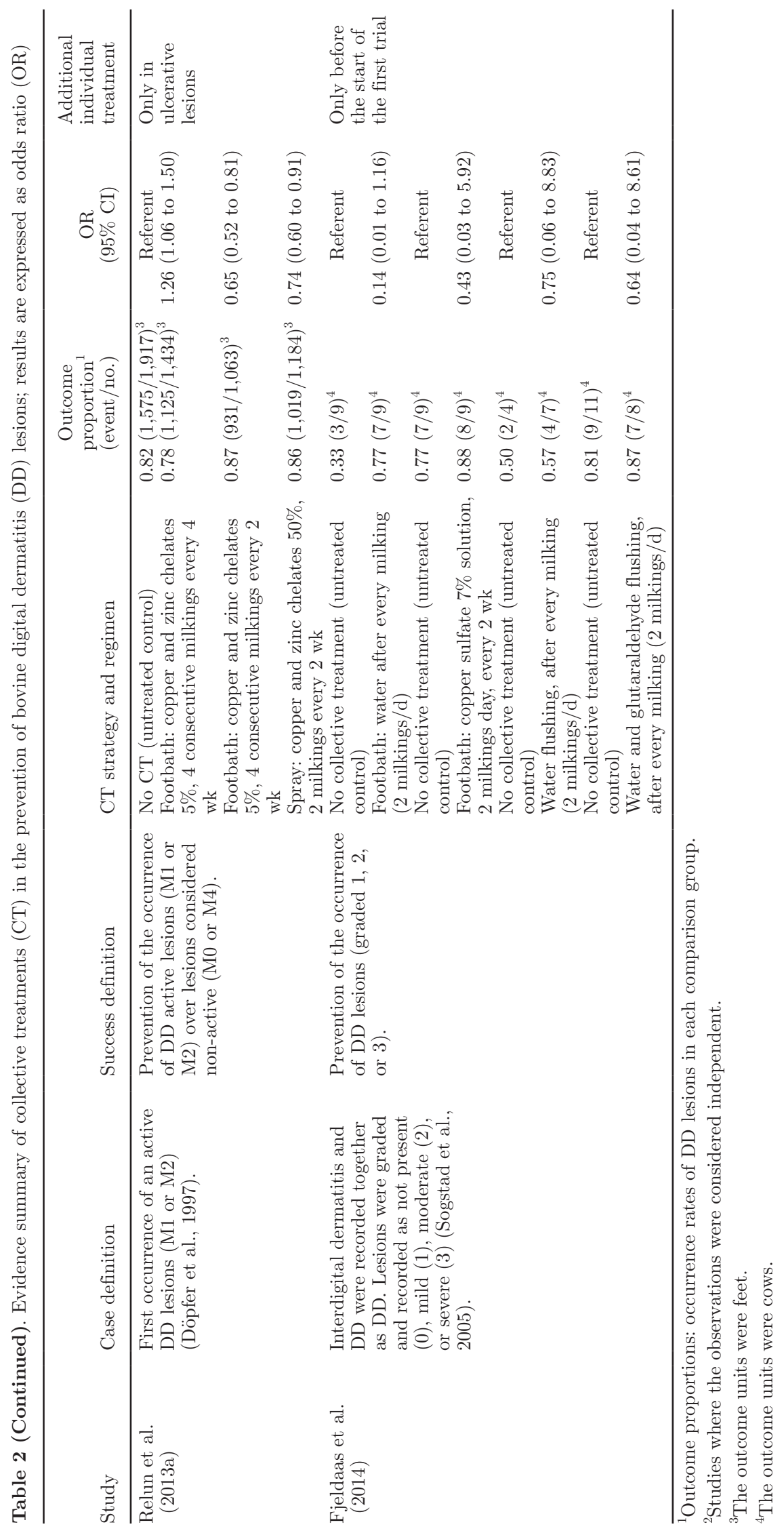




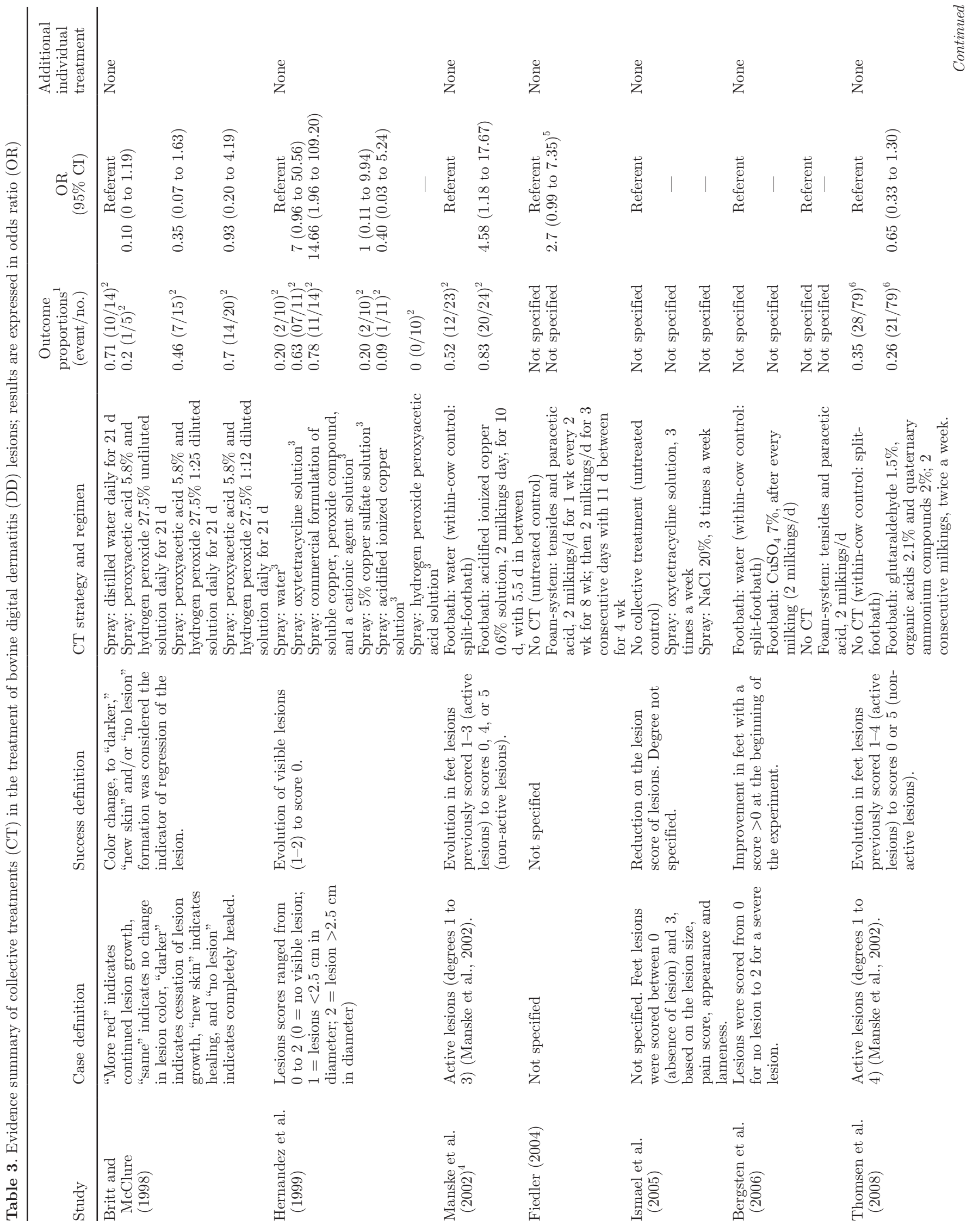


SYSTEMATIC REVIEW: COLLECTIVE TREATMENT OF BOVINE DIGITAL DERMATITIS

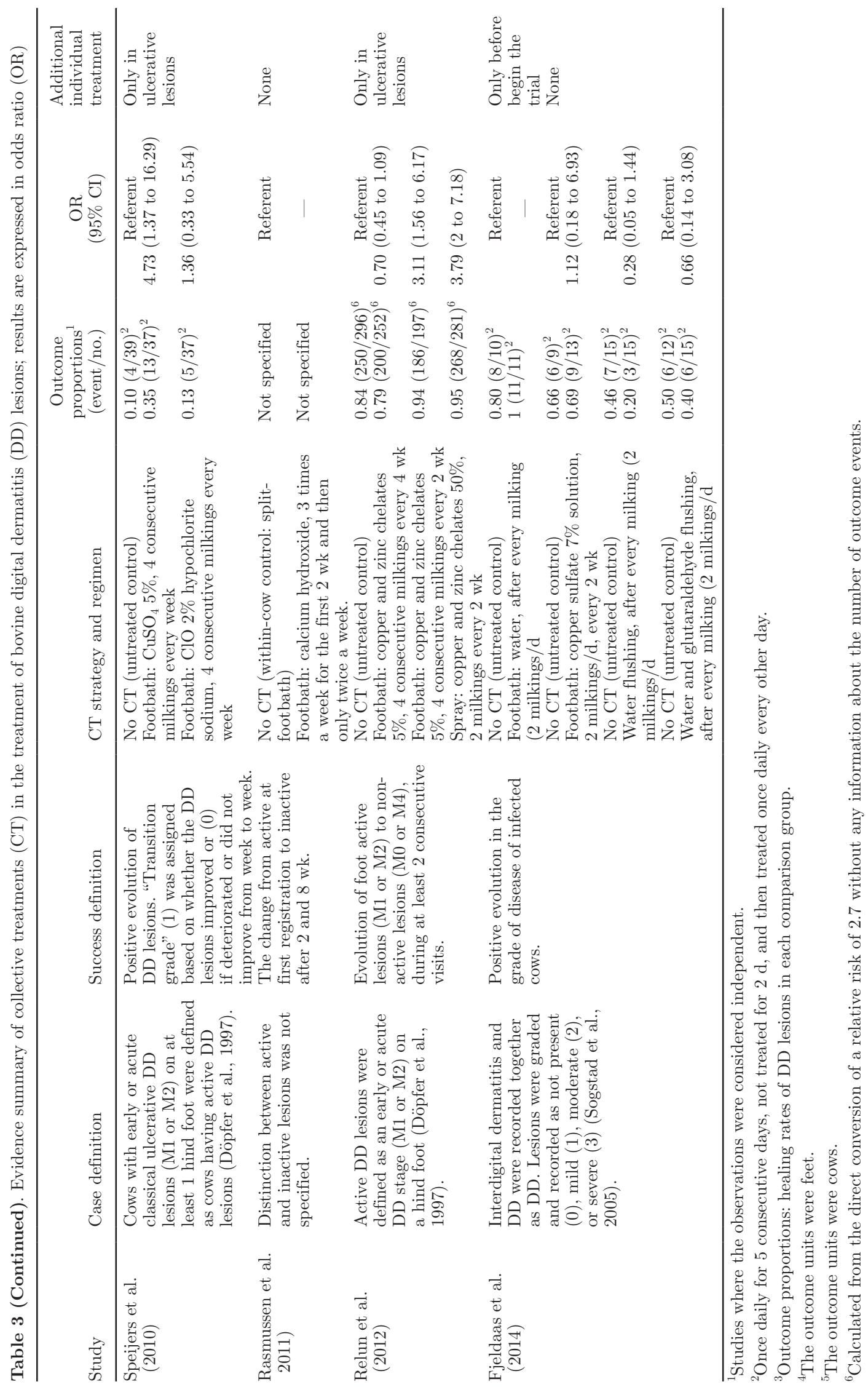




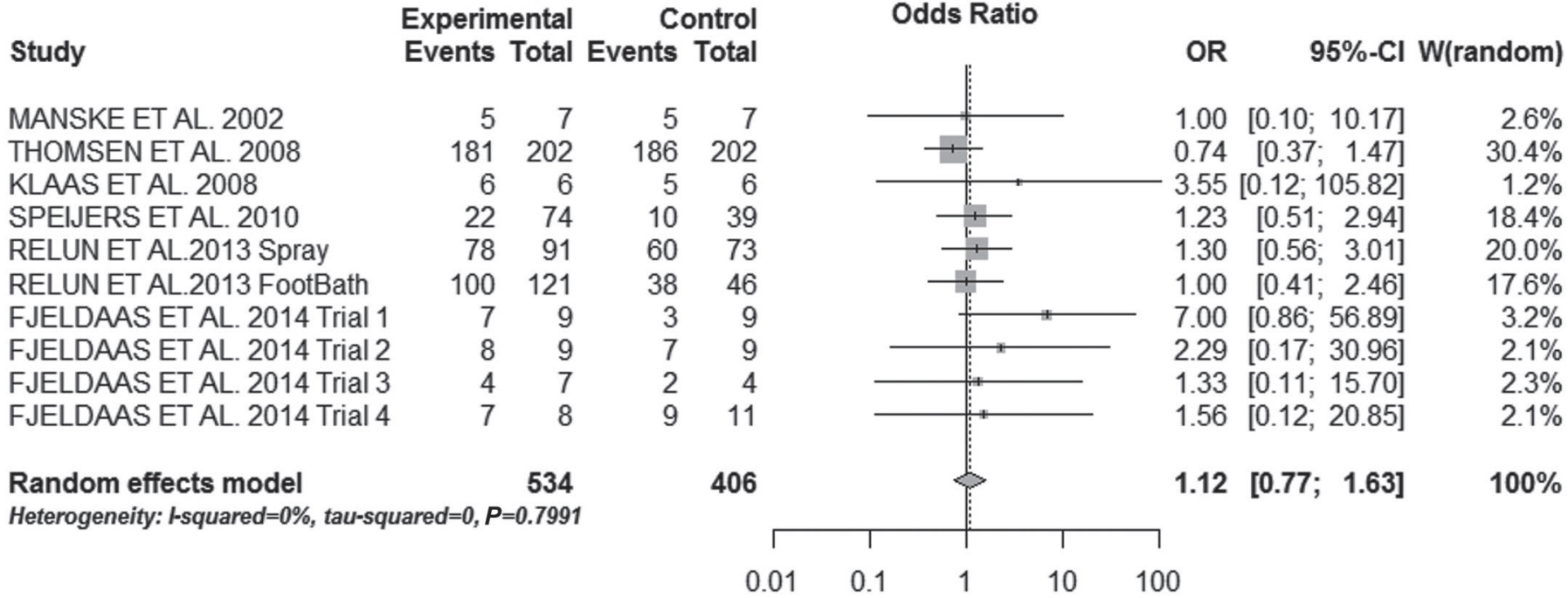

Figure 3. Meta-analyses forest plot of odds ratios (OR) and 95\% CI for 10 trials (comparisons) investigating the effectiveness of collective treatments $(\mathrm{CT})$, compared with no treatment or the use of a placebo, in reducing the occurrence of digital dermatitis (DD) lesions. Point estimates and $95 \%$ CI for each study are presented on each line. Relative weighting [W (random)] of each study is represented by the gray box surrounding the point estimate. Combined effect estimates (diamond) are presented at the bottom of the graph. Studies are listed chronologically by first author's last name and year only.

system (2), footmat (1), and automatic flushing (1). Only one study reported adverse events related to the collective administration of calcium hydroxide (Rasmussen et al., 2011). For the prevention of DD lesions, the OR ranged from 0.14 to 1.31 . For the healing of DD lesions, the OR ranged from 0.10 to 14.66 . In only 3 of the 18 prevention comparisons the null value was not contained within the OR $95 \%$ CI, whereas for the treatment outcome, in 5 of the 24 comparisons, the null value was not contained in the calculations.

\section{Synthesis of Results}

Prevention Outcome. For the 10 prevention comparisons included in the synthesis, the summary OR was 1.12 (95\% CI 0.76 to $1.62 ; P=0.56)$, suggesting that the uncertainty of the CT effect extends from no prevention to prevention (Figure 3). The visual appraisal of the L'Abbé plot suggests the absence of heterogeneity, with most of the plots displayed close or over the equality line, and a cluster formation on the extremes of the $\mathrm{y}$ - and $\mathrm{x}$-axes (Figure 4A). The heterogeneity measures were consistent with the graphical findings [Cochran's Q test $(P=0.79) ; I^{2}=0 \%, 95 \%$ CI: 0 to $37.2 \%$; and $\left.\tau^{2}=0\right]$. The calculated $95 \%$ PI ranged from 0.72 to 1.74 . Subgroup analyses did not demonstrate any differences in the prevention effect (Table 4).

The funnel plot was slightly asymmetrical (Figure 4B), and suggested that larger trials were more likely to report effects closer to the null value (no effect). These findings were likewise confirmed by the Harbord's test $(P=0.04)$.

Treatment Outcome. For the 11 treatment comparisons included in the synthesis (Figure 5), the summary OR was 1.22 (95\% CI: 0.73 to $2.01 ; P=0.44)$. The L'Abbé plot displayed a dispersed pattern indicative of considerable heterogeneity (Figure 6A). The heterogeneity assessments suggested a small degree of heterogeneity between the included studies (Cochran's Q test, $P=0.20 ; I^{2}=25.3 \%, 95 \%$ CI: 0 to $63 \% ; \tau^{2}$ $=0.1779)$. The calculated $95 \%$ PI ranged from 0.39 to 3.73. Subgroup analysis by study design (subgroup Cochran's Q test, $P=0.02$ ) suggested a qualitative interaction in favor of NRCS design (OR $=1.99 ; 95 \%$ CI: 1.08 to 3.66). Likewise, subgroup analysis by followup assessment (subgroup Cochran's Q test, $P=0.04$ ) suggested a qualitative interaction in favor of multipleoutcomes assessments (OR $=1.95 ; 95 \%$ CI: 1.03 to 3.68). The remaining subgroups assessed showed no association with the healing effect (Table 4).

The funnel plot was slightly asymmetrical (Figure 6B), suggesting possible publication bias. However, these findings were not confirmed by Harbord's test $(P$ $=0.55)$.

Taken together, for the prevention and treatment outcomes, the heterogeneity assessments revealed an uncertain degree of inconsistency across the included evidence. Although the summary effect and the heterogeneity findings cannot be interpreted, they are presented as valuable information for the reader. 


\section{DISCUSSION}

This systematic review summarized the body of current literature describing the effectiveness of $\mathrm{CT}$ in the treatment and prevention of DD lesions in dairy cattle. The evidence was supported by studies considered to be mostly at low and unclear risk of bias. The review results indicated a low degree of heterogeneity across the evidence for the prevention outcome. Nevertheless, for the treatment outcome, the considerable degree of heterogeneity across the evidence suggested the presence of inconsistency, indicating that the summary effect calculation is not sensible. Likewise, imprecision was suspected due to the frequent small samples sizes of trials and the fact that for most of the studies, when evaluating the prevention or the treatment outcome, the $95 \%$ CI were wide and included the null effect. Additionally, possible publication bias was considered for the treatment and prevention outcomes. The overall quality of the evidence for both outcomes (prevention and treatment) was therefore considered to be low, indicating that the true effect of CT may be substantially different from the summary effect estimated by the meta-analysis.

The broad literature search conducted in this review, including gray literature sources and the main databases of veterinary and animal science journals (Grindlay et al., 2012), led to a spectrum of available literature, reducing the selection bias in the review process. Gray literature sources are important to consider, especially in veterinary science, where a large part of the research is reported only through conference proceedings (Brace et al., 2010). However, manual searches were time consuming, the publications obtained for this review were mostly unclear or not sufficiently detailed for their data abstraction, and contacting the authors was difficult or unfeasible in some cases. Finally, and regardless of search strategy efforts, only a few studies were included in the summary and synthesis because of the limited number of interventional studies and clinical trials including an untreated or placebo control comparison group in their design. These findings coincide with the search results from a previous descriptive review study on the treatment and prevention of cattle lameness (Potterton et al., 2012), where the number of intervention studies and clinical trials was low and most of the papers on prevention were observational and analytic epidemiologic studies. The screening process targeted only trials evaluating the incidence and the healing of DD lesions, resulting in the non-inclusion of prevalence studies, which are possible sources of evidence in favor of CT usage. Nevertheless, because exposure and disease status are measured at the same time point in cross-sectional studies, it may not always be possible
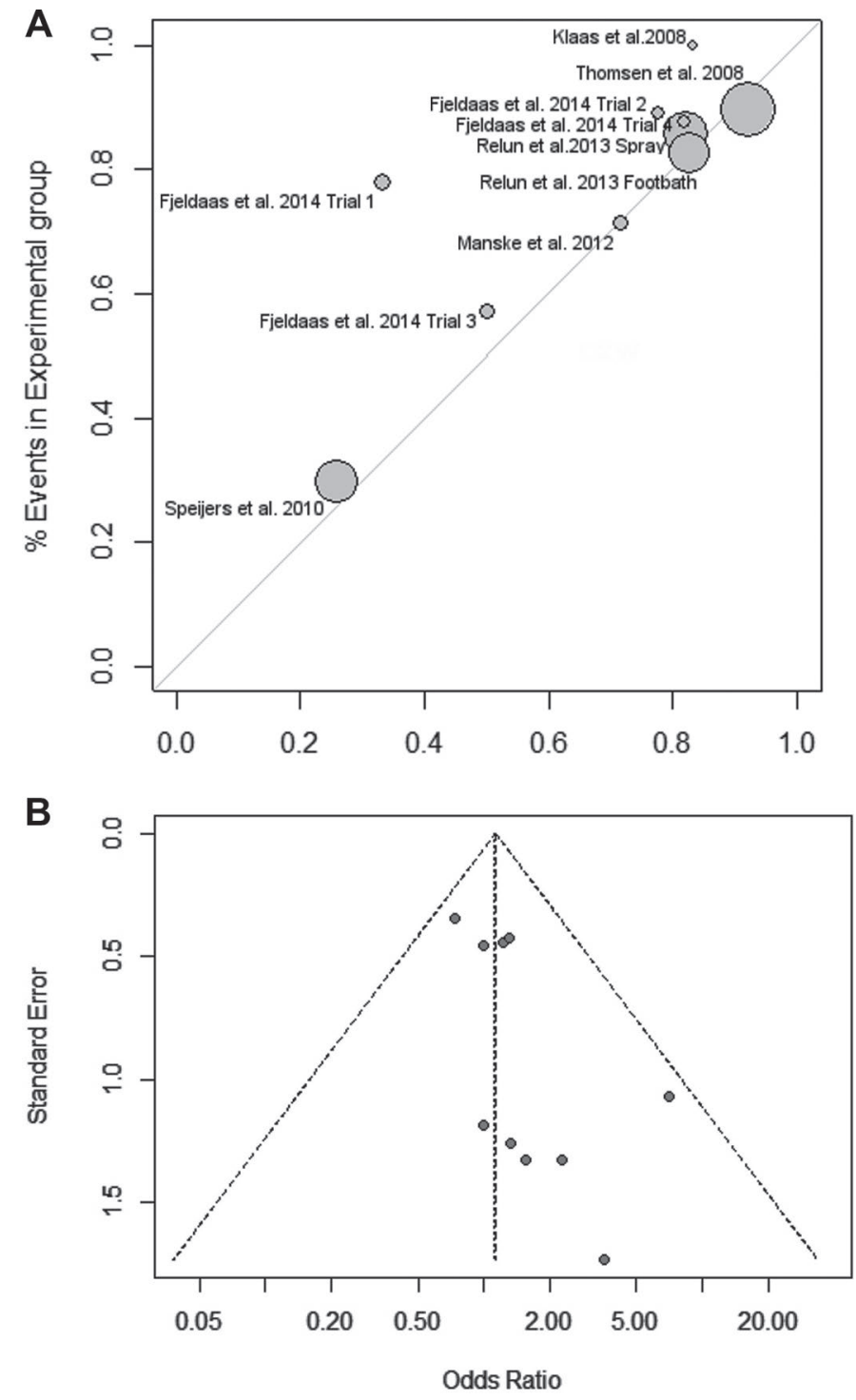

Figure 4. Heterogeneity assessments of the prevention outcome: (A) L'Abbé plot for trials evaluating the prevention of bovine digital dermatitis (DD) lesions; trials were plotted according to the beneficial superiority on the comparison of event proportions between the collective treatments (CT) group and the control group, with point size being proportional to the size of the trial; (B) funnel plot of the summary odds ratio (vertical dashed line) of studies involved in the prevention of DD lesions. Each trial is represented by a gray circle.

to distinguish whether the intervention preceded or followed the appearance of DD lesions, and thus the relationship between cause and effect remains unclear or is concealed among the possible effects of the risk factors associated with the disease.

The main limitation of this meta-analysis, as with any other synthesis, was the differences across studies in terms of dairy cow populations, CT regimens, and outcomes definitions. Nonetheless, a comparable methodology for the outcome measure was used in the stud- 
Table 4. Subgroup analysis assessing the effectiveness of collective treatments (CT) in the prevention and treatment of bovine digital dermatitis (DD) lesions

\begin{tabular}{|c|c|c|c|c|c|c|c|}
\hline Subgroup $^{1}$ & $\begin{array}{l}\text { Number } \\
\text { of trials }\end{array}$ & $\begin{array}{l}\text { Odds } \\
\text { ratio }\end{array}$ & $95 \% \mathrm{CI}$ & $P$-value & \multicolumn{3}{|c|}{ Heterogeneity $^{2}$} \\
\hline \multicolumn{8}{|l|}{ Preventive outcome } \\
\hline \multicolumn{8}{|l|}{ Study design } \\
\hline NRCS & 5 & 1.19 & 0.73 to 1.93 & 0.47 & 0 & 0.67 & 0.73 \\
\hline Low $(<30 \%)$ & 4 & 0.96 & 0.61 to 1.52 & 0.88 & 0 & \multirow[t]{2}{*}{0.26} & \multirow[t]{2}{*}{0.84} \\
\hline $\operatorname{High}(>30 \%)$ & 6 & 1.54 & 0.78 to 3.03 & 0.20 & 0 & & \\
\hline \multicolumn{8}{|l|}{ Length of the study } \\
\hline More than 8 wk & 7 & 1.34 & 0.79 to 2.29 & 0.27 & 0 & \multirow[t]{2}{*}{0.33} & \multirow[t]{2}{*}{0.81} \\
\hline Up to $8 \mathrm{wk}$ & 3 & 0.92 & 0.54 to 1.57 & 0.78 & 0 & & \\
\hline \multicolumn{8}{|l|}{ Follow-up assessments } \\
\hline Only before and after outcome observations & 7 & 1.04 & 0.59 to 1.84 & 0.87 & 0 & 0.76 & 0.72 \\
\hline \multicolumn{8}{|l|}{ Study design } \\
\hline NRCS & 4 & 1.99 & 1.08 to 3.66 & 0.02 & 0.4 & \multirow[t]{2}{*}{0.02} & \multirow[t]{2}{*}{0.48} \\
\hline $\mathrm{RCT}$ & 7 & 0.77 & 0.43 to 1.38 & 0.48 & 0 & & \\
\hline \multicolumn{8}{|l|}{ Initial prevalence } \\
\hline Low $(<30 \%)$ & 3 & 1.27 & 0.54 to 2.98 & 0.56 & 55 & \multirow[t]{2}{*}{0.14} & 0.88 \\
\hline High $(>30 \%)$ & 8 & 1.18 & 0.58 to 2.39 & 0.64 & 21.8 & & \\
\hline Length of the study & & & & & & & \\
\hline More than 8 wk & 7 & 1.22 & 0.59 to 2.53 & 0.57 & 27.8 & 0.98 & 0.14 \\
\hline Up to $8 \mathrm{wk}$ & 4 & 1.21 & 0.53 to 2.74 & 0.64 & 41 & & \\
\hline Follow-up assessments & & & & & & & \\
\hline Only before and after outcome observations & 8 & 0.81 & 0.45 to 1.44 & 0.48 & 0 & 0.04 & 0.41 \\
\hline Multiple outcomes observations & 3 & 1.95 & 1.03 to 3.68 & 0.04 & 29.6 & & \\
\hline Study limitations & & & & & & & \\
\hline Low risk of bias & 5 & 1.22 & 0.60 to 2.45 & 0.57 & 34.6 & 1.00 & 0.14 \\
\hline
\end{tabular}

${ }^{1} \mathrm{NRCS}=$ nonrandomized controlled study; $\mathrm{RCT}=$ randomized controlled trial.

${ }^{2} I^{2}=$ statistic that describes the proportion of total variation in study effect estimates that is due to heterogeneity.

ies included, and therefore we considered that the data across the studies could be combined to estimate CT effectiveness with more precision than in a single study. In the context of this review, the number of follow-up assessments and the length of the follow-up periods were considered to have an important influence on the precision of the effect estimate, especially given that the reported median time before the occurrence of a new DD lesion is 5 mo (Relun et al., 2013a; Krull et al., 2016), and that DD lesions can be completely healed within 1 mo (Holzhauer et al., 2008). The subgroup analyses that investigated the importance of these factors suggested a qualitative interaction in favor of studies using multiple-outcomes observations and for NRCS designs to evaluate the treatment outcome. However, the assessments of the subgroup analyses were limited by the small number of studies. Likewise, as different lesion scoring methodologies were used across studies, the case and success definitions were different. There- fore, to harmonize the results of future clinical trials, it is crucial to homogenize the classification system of lesions to set uniform objectives for control strategies. Independent of the method used to score DD lesions, chronic non-ulcerative lesions might be considered nonactive stages and consequently a successful target stage. However, it is unknown whether these lesions are truly healed (Döpfer et al., 2012) or to what degree they represent a risk factor stage for the relapse of ulcerative lesions and spread of the disease.

The uncertain extension and degree of heterogeneity across studies guide us to approach the meta-analysis using a random-effects model. The frequent small size of the trials, probably due to practical, ethical, and financial reasons, represents a large part of the imprecision evidenced across the studies. Nevertheless, in contrast to what would be expected based on the low number of studies included and their small size, the confidence intervals for the summary effect estimates were relatively 


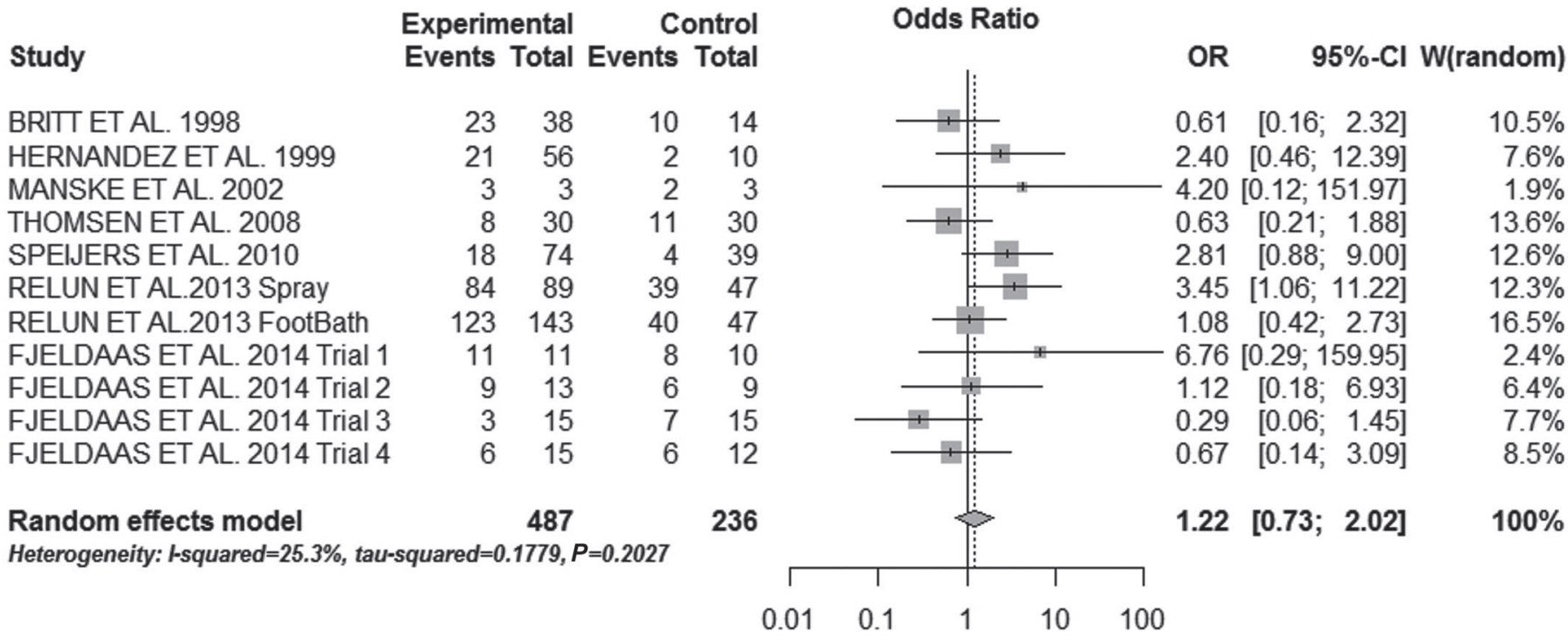

Figure 5. Meta-analyses forest plot of odds ratios (OR) and 95\% CI for 11 trials (comparisons) investigating the effectiveness of collective treatments (CT), compared with no treatment or the use of a placebo, in healing digital dermatitis (DD) lesions. Point estimates and 95\% CI for each study are presented on each line. Relative weighting [W (random)] of each study is represented by the gray box surrounding the point estimate. Combined effect estimates (diamond) are presented at the bottom of the graph. Studies are listed chronologically by first author's last name and year only.

narrow. An alternative to reduce sample sizes would be trials designed for paired within-cow comparisons. However, depending on the statistical methods used, these designs could entail some problems related to disease prevalence and the fact that both legs (treatment and control) must share the same lesion status, a requirement that leads to possible important losses of statistical power, or otherwise, to biased interpretations in the cases where the analysis ignores the dependence between the legs of the same cow. Performance and detection bias related to blinding were limited across the studies by the objective measure of lesion evolution and, in some cases, when co-interventions were adjusted for in the analyses.

Another limitation encountered in the synthesis process was related to water treatments used in placebo control groups that might have induced a beneficial effect on DD lesions by controlling feet hygiene, a risk factor associated with the spread of DD. This limitation leads to final interpretation bias. The correlation between the healing and the occurrence of DD lesions could entail some issues for studies that evaluate prevention and treatment outcomes in parallel. However, in such studies, the degree to which the CT effects could be over- or underestimated is uncertain because of the contagious dynamics of the disease. Across the studies included in the synthesis, some risks of carryover bias were evidenced, mostly because washout periods between trials were not feasible, probably for financial and practical reasons. The frequent attrition bias evi- denced in some of the studies was the result of unclear methodologies for dealing with missing data or when imbalances generated by exclusions were not reported.

Different limitations were associated with the low number of studies included in the quantitative synthesis and, consequently, the insufficient statistical power for heterogeneity and publication bias tests. Nevertheless, the strategy implemented to assess heterogeneity across the evidence was to integrate visual and statistical methodologies to allow an integral approach to the evidence and avoid possible problems related to the small number of studies and statistical power. Therefore, even if statistical heterogeneity was barely evidenced, the L'Abbé plot allowed a broad heterogeneity assessment. Likewise, the calculated 95\% PI for the treatment outcome was wider than the $95 \%$ CI, suggesting the presence of heterogeneity in the sample. Because of statistical considerations, publication bias was difficult to evaluate and cannot be excluded. In particular, the absence of intervention effect on both outcomes renders the appreciation of asymmetry difficult. Although the low number of publications may be explained by the difficulties in conducting effectiveness trials in veterinary science for ethical and economic reasons, most of the DD studies are sponsored by private funding, and possible negative results could remain unpublished, as in the case of human medical sciences (Hopewell et al., 2009).

The lack of scientific evidence supporting the effectiveness of $\mathrm{CT}$ found in this paper is in agreement with 

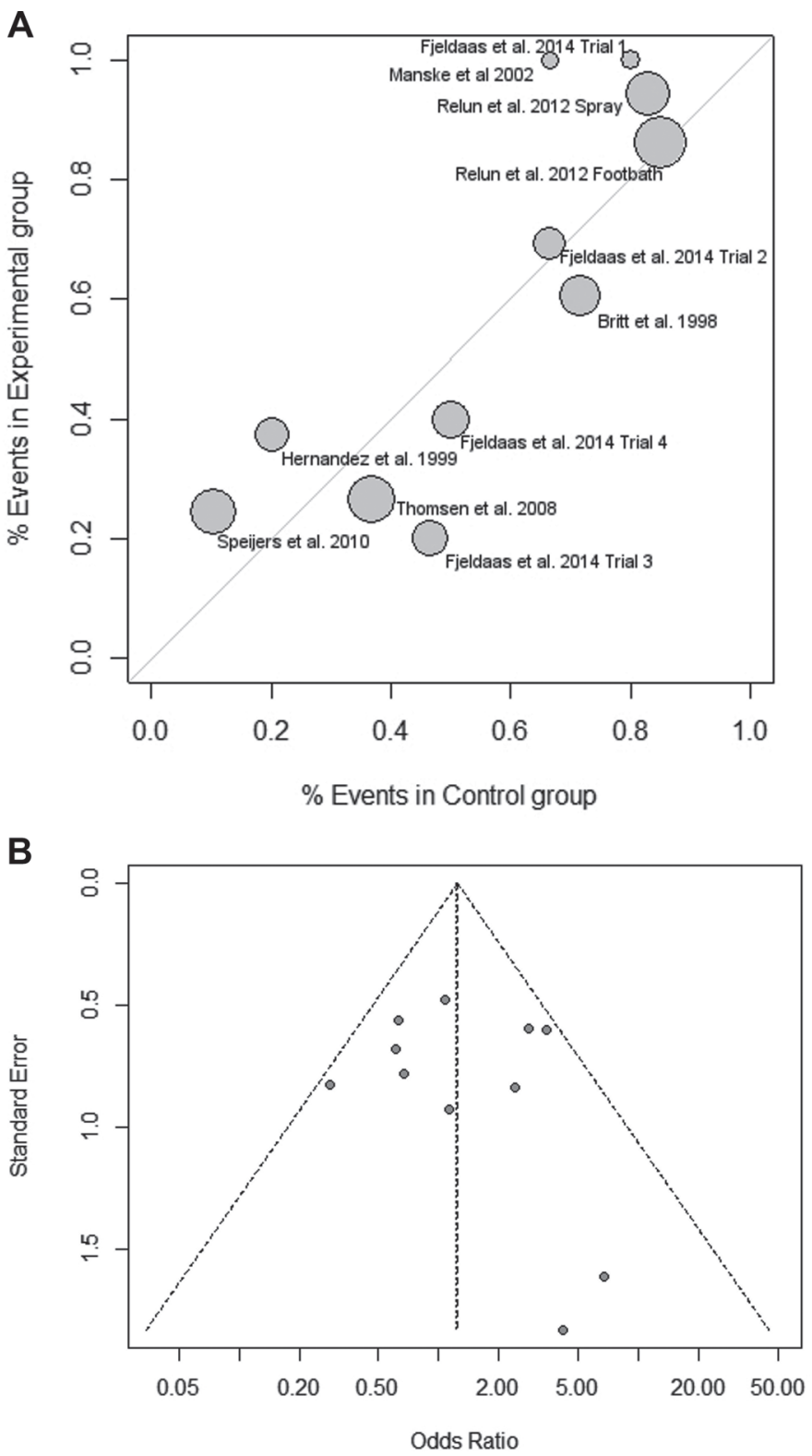

Figure 6. Heterogeneity assessments of the treatment outcome: (A) L'Abbé plot for trials evaluating the treatment of bovine digital dermatitis (DD) lesions; trials were plotted according to the beneficial superiority on the comparison of event proportions between the collective treatments (CT) group and the control group, with point size being proportional to the size of the trial; (B) funnel plots of the summary odds ratio (vertical dashed line) of studies involved in the treatment of DD lesion. Each trial is represented by a gray circle.

the conclusions of a previous review paper (Laven and Logue, 2006). Our findings highlight the constraints faced by collective intervention trials and point to the need for research into the development and design of high-quality protocols to evaluate the effectiveness of collective interventions. Based on our findings, we propose that future protocols for the assessment of the effectiveness of $\mathrm{CT}$ in the prevention or treatment of $\mathrm{DD}$ lesions must include the following key elements: (1) reduction of confounding and selection bias through randomization or other comparable methods; (2) negative untreated controls to compare with the experimental treatment (avoid placebo water controls); (3) an objective measure of DD lesion evolution, clearly describing case and success definitions, for the outcomes assessments; (4) multiple observations by trained assessors at intervals no longer than 1 mo within the follow-up period; (5) longer follow-up periods of at least 5 mo; (6) sample sizes determined for statistical power; and (7) co-interventions or other confounding variables (e.g., individual treatment of active lesions) that are adjusted for in the analysis.

\section{CONCLUSIONS}

Practitioners, animal health advisors, farmers, and the veterinary health industry must be informed that the preventive and treatment effectiveness of CT remains uncertain, and the epidemiological circumstances in which they can be useful must be further investigated. This systematic review and meta-analyses demonstrated that the number of studies was small and the quality of the evidence was low. A standardized protocol and high-quality clinical trials are urgently needed to investigate the effectiveness of $\mathrm{CT}$ in the treatment and prevention of DD lesions.

\section{ACKNOWLEDGMENTS}

We acknowledge the authors of publications who provided the supplementary information requested for this review. Additionally, we thank A. Lehebel, F. Beaudeau, and A. Madouasse (BIOEPAR, INRA, Oniris, Nantes, France) for helpful discussions on the statistical analyses and $\mathrm{R}$ programming. This study was funded as part of a PhD studentship by Qalian (Neovia, Segré, France) and the Association Nationale de la Recherche et de la Technologie (ANRT, Paris, France). The funding sources did not participate in any way in the conception and design of the study, the collection, analysis, and interpretation of the data, the writing of the review, or in the decision to submit the paper for publication.

\section{REFERENCES}

Apley, M. D. 2015. Clinical evidence for individual animal therapy for papillomatous digital dermatitis (hairy heel wart) and infectious bovine pododermatitis (foot rot). Vet. Clin. North Am. Food Anim. Pract. 31:81-95. https://doi.org/10.1016/j.cvfa.2014.11.009.

Bergsten, C., J. Hultgren, and A. Hillstrom. 2006. Using a footbath with copper sulphate or peracetic foam for the control of digital dermatitis and heel horn erosion in a dairy herd. Pages 61-62 in Proc. 14th Int. Symp., 6th Conf. Lameness in Ruminants, Colonia 
del Sacramento, Uruguay. Accessed Mar. 5, 2016. http://www.ivis. org/proceedings/RumLameness/2006/toc.asp.

Berry, S. L., D. H. Read, T. R. Famula, A. Mongini, and D. Döpfer. 2012. Long-term observations on the dynamics of bovine digital dermatitis lesions on a California dairy after topical treatment with lincomycin HCl. Vet. J. 193:654-658. https://doi.org/10.1016/j. tvj1.2012.06.048.

Borenstein, M., J. P. T. Higgins, L. V. Hedges, and H. R. Rothstein. 2017. Basics of meta-analysis: $I^{2}$ is not an absolute measure of heterogeneity. Res. Synth. Methods https://doi.org/10.1002/ jrsm.1230.

Brace, S., D. Taylor, and A. M. O'Connor. 2010. The quality of reporting and publication status of vaccines trials presented at veterinary conferences from 1988 to 2003. Vaccine 28:5306-5314. https://doi. org/10.1016/j.vaccine.2010.05.041.

Britt, J., and J. McClure. 1998. Field trials with antibiotic and non antibiotic treatments for papillomatous digital dermatitis. Bovine Pract. 32:25-28.

Brown, C. C., P. D. Kilgo, and K. L. Jacobsen. 2000. Prevalence of papillomatous digital dermatitis among culled adult cattle in the southeastern United States. Am. J. Vet. Res. 61:928-930. https:// doi.org/10.2460/ajvr.2000.61.928.

Bruijnis, M. R. N., B. Beerda, H. Hogeveen, and E. N. Stassen. 2012. Assessing the welfare impact of foot disorders in dairy cattle by a modeling approach. Animal 6:962-970. https://doi.org/10.1017/ S1751731111002606.

Bruijnis, M. R. N., H. Hogeveen, and E. N. Stassen. 2010. Assessing economic consequences of foot disorders in dairy cattle using a dynamic stochastic simulation model. J. Dairy Sci. 93:2419-2432. https://doi.org/10.3168/jds.2009-2721.

Cramer, G., K. D. Lissemore, C. L. Guard, K. E. Leslie, and D. F. Kelton. 2008. Herd- and cow-level prevalence of foot lesions in Ontario dairy cattle. J. Dairy Sci. 91:3888-3895. https://doi.org/10.3168/ jds.2008-1135.

DerSimonian, R., and N. Laird. 1986. Meta-analysis in clinical trials. Control. Clin. Trials 7:177-188.

Döpfer, D., A. Koopmans, F. A. Meijer, I. Szakáll, Y. H. Schukken, W. Klee, R. B. Bosma, J. L. Cornelisse, A. J. van Asten, and A. A. ter Huurne. 1997. Histological and bacteriological evaluation of digital dermatitis in cattle, with special reference to spirochaetes and Campylobacter faecalis. Vet. Rec. 140:620-623. https://doi. org/10.1136/vr.140.24.620.

Döpfer, D., K. Anklam, D. Mikheil, and P. Ladell. 2012. Growth curves and morphology of three Treponema subtypes isolated from digital dermatitis in cattle. Vet. J. 193:685-693. https://doi. org/10.1016/j.tvjl.2012.06.054.

Ettema, J., S. Østergaard, and A. R. Kristensen. 2010. Modelling the economic impact of three lameness causing diseases using herd and cow level evidence. Prev. Vet. Med. 95:64-73. https://doi. org/10.1016/j.prevetmed.2010.03.001.

Fiedler, A. 2004. Investigation of the efficacy of the kovex-foam-system in the decrease of the incidence of dermatitis digitalis; dermatitis interdigitalis and erosio ungulae. Pages 20-22 in Proc. 13th Int. Symp., 5th Conference on Lameness in Ruminants, Maribor, Slovenia. Unugla, Zemljic \& Co., Maribor, Slovenia.

Fjeldaas, T., K. E. Bøe, and R. B. Larssen. 2014. Water footbath, automatic flushing, and disinfection to improve the health of bovine feet. J. Dairy Sci. 97:2835-2846. https://doi.org/10.3168/jds.20137531.

Gomez, A., N. B. Cook, N. D. Bernardoni, J. Rieman, A. F. Dusick, R. Hartshorn, M. T. Socha, D. H. Read, and D. Döpfer. 2012. An experimental infection model to induce digital dermatitis infection in cattle. J. Dairy Sci. 95:1821-1830. https://doi.org/10.3168/ jds.2011-4754.

Grindlay, D. J. C., M. L. Brennan, and R. S. Dean. 2012. Searching the veterinary literature: A comparison of the coverage of veterinary journals by nine bibliographic databases. J. Vet. Med. Educ. 39:404-412. https://doi.org/10.3138/jvme.1111.109R.

Hartshorn, R. E., E. C. Thomas, K. Anklam, M. G. Lopez-Benavides, M. Buchalova, T. C. Hemling, and D. Döpfer. 2013. Short communication: Minimum bactericidal concentration of disinfectants evaluated for bovine digital dermatitis-associated Treponema phagedenis-like spirochetes. J. Dairy Sci. 96:3034-3038. https:// doi.org/10.3168/jds.2012-5994.

Hernandez, J., J. K. Shearer, and J. B. Elliott. 1999. Comparison of topical application of oxytetracycline and four nonantibiotic solutions for treatment of papillomatous digital dermatitis in dairy cows. J. Am. Vet. Med. Assoc. 214:688-690.

Higgins, J. P. T., D. G. Altman, P. C. Gotzsche, P. Juni, D. Moher, D. Oxman, J. Savovic, K. F. Schulz, L. Weeks, and J. C. Sterne. 2011. The Cochrane Collaboration's tool for assessing risk of bias in randomised trials. BMJ 343:d5928. https://doi.org/10.1136/ bmj.d5928.

Higgins, J. P. T., and S. Green, ed. 2011. Cochrane Handbook for Systematic Reviews of Interventions. Version 5.1.0; updated March 2011. Accessed Jun. 15, 2017. http://handbook.cochrane.org/.

Higgins, J. P. T., and S. G. Thompson. 2002. Quantifying heterogeneity in a meta-analysis. Stat. Med. 21:1539-1558. https://doi. org/10.1002/sim.1186.

Holzhauer, M., C. J. M. Bartels, D. Dopfer, and G. van Schaik. 2008. Clinical course of digital dermatitis lesions in an endemically infected herd without preventive herd strategies. Vet. J. 177:222230. https://doi.org/10.1016/j.tvjl.2007.05.004.

Holzhauer, M., C. J. M. Bartels, B. H. P. van den Borne, and G. van Schaik. 2006a. Intra-class correlation attributable to claw trimmers scoring common hind-claw disorders in Dutch dairy herds. Prev. Vet. Med. 75:47-55. https://doi.org/10.1016/j. prevetmed.2006.01.013.

Holzhauer, M., C. Hardenberg, C. J. M. Bartels, and K. Frankena. 2006b. Herd- and cow-level prevalence of digital dermatitis in the Netherlands and associated risk factors. J. Dairy Sci. 89:580-588. https://doi.org/10.3168/jds.S0022-0302(06)72121-X.

Hopewell, S., K. Loudon, M. J. Clarke, A. D. Oxman, and K. Dickersin. 2009. Publication bias in clinical trials due to statistical significance or direction of trial results. Cochrane Database Syst. Rev. https://doi.org/10.1002/14651858.MR000006.pub3.

Ippolito, J. A., T. Ducey, and D. Tarkalson. 2010. Copper impacts on corn, soil extractability, and the soil bacterial community. Soil Sci. 175:586-592. https://doi.org/10.1097/SS.0b013e3181fe2960.

Ishmael, R., T. Goodman, J. Martin, and C. Stockwell. 2005. A comparison of the effectiveness of oxytetracycline or salt water in the management of digital dermatitis in dairy cattle. Page 207 in Proc. Br. Soc. Anim. Sci., York, UK. British Society of Animal Science, Penicuik, UK.

Klaas, I., K. Krogh, and J. T. Sorensen. 2008. The effect of two different footbath solutions on digital dermatitis. Pages 9-12 in Proc. 15th Int. Symp., 7th Conf. on Lameness in Ruminants, Kuopio, Finland. Savonia University of Applied Sciences, Kuopio, Finland.

Krull, A. C., J. K. Shearer, P. J. Gorden, H. M. Scott, and P. J. Plummer. 2016. Digital dermatitis: Natural lesion progression and regression in Holstein dairy cattle over 3 years. J. Dairy Sci. 99:3718-3731. https://doi.org/10.3168/jds.2015-10535.

L'Abbé, K. A., A. S. Detsky, and K. O'Rouke. 1987. Meta-analysis in clinical research. Ann. Intern. Med. 107:224-233. https://doi. org/10.7326/0003-4819-107-2-224.

Laven, R. A., and D. N. Logue. 2006. Treatment strategies for digital dermatitis for the UK. Vet. J. 171:79-88. https://doi. org/10.1016/j.tvjl.2004.08.009.

Manske, T., J. Hultgren, and C. Bergsten. 2002. Topical treatment of digital dermatitis associated with severe heel-horn erosion in a Swedish dairy herd. Prev. Vet. Med. 53:215-231. https://doi. org/10.1016/S0167-5877(01)00268-9.

Palmer, M. A., R. F. Donnelly, M. J. Garland, R. Majithiya, and N. E. O'Connell. 2013. The effect of slurry on skin permeability to methylene blue dye in dairy cows with and without a history of digital dermatitis. Animal 7:1731-1737. https://doi.org/10.1017/ S1751731113001274.

Potterton, S. L., N. J. Bell, H. R. Whay, E. A. Berry, O. C. D. Atkinson, R. S. Dean, D. C. J. Main, and J. N. Huxley. 2012. A descriptive review of the peer and non-peer reviewed literature on the treatment and prevention of foot lameness in cattle pub- 
lished between 2000 and 2011. Vet. J. 193:612-616. https://doi. org/10.1016/j.tvjl.2012.06.040.

R Core Team. 2015. R: A Language and Environment for Statistical Computing. R Core Team, Vienna, Austria.

Rasmussen, A., N. Capion, and T. W. Bennedsgaard. 2011. Evaluation of calcium hydroxide $(\mathrm{Ca}(\mathrm{OH}) 2)$ used in footbaths as treatment and prevention of digital dermatitis in Danish dairy cattle. Page 136 in Proc. 16th Int. Symp., 8th Conf. Lameness in Ruminants, Rotorua, New Zealand. Accessed May 20, 2016. http://www.ivis. org/proceedings/RumLameness/2011/toc.asp.

Relun, A., R. Guatteo, M. M. Auzanneau, and N. Bareille. 2013b. Farmers' practices, motivators and barriers for adoption of treatments of digital dermatitis in dairy farms. Animal 7:1542-1550. https://doi.org/10.1017/S1751731113000803.

Relun, A., A. Lehebel, N. Bareille, and R. Guatteo. 2012. Effectiveness of different regimens of a collective topical treatment using a solution of copper and zinc chelates in the cure of digital dermatitis in dairy farms under field conditions. J. Dairy Sci. 95:3722-3735. https://doi.org/10.3168/jds.2011-4983.

Relun, A., A. Lehebel, M. Bruggink, N. Bareille, and R. Guatteo. 2013a. Estimation of the relative impact of treatment and herd management practices on prevention of digital dermatitis in French dairy herds. Prev. Vet. Med. 110:558-562. https://doi. org/10.1016/j.prevetmed.2012.12.015.

Relun, A., A. Lehebel, A. Chesnin, R. Guatteo, and N. Bareille. 2013c. Association between digital dermatitis lesions and test-day milk yield of Holstein cows from 41 French dairy farms. J. Dairy Sci. 96:2190-2200. https://doi.org/10.3168/jds.2012-5934.

Richardson, W. S., M. C. Wilson, J. Nishikawa, and R. S. Hayward 1995. The well-built clinical question: A key to evidence-based decisions. ACP J. Club 123:A12-A13.
Sargeant, J. M., D. F. Kelton, and M. O'Connor. 2014. Study designs and systematic reviews of interventions: Building evidence across study designs. Zoonoses Public Health 61:10-17. https:// doi.org/10.1111/zph.12127.

Sargeant, J. M., and M. O'Connor. 2014. Introduction to systematic reviews in animal agriculture and veterinary medicine. Zoonoses Public Health 61:3-9. https://doi.org/10.1111/zph.12128.

Schwarzer, G. 2015. Meta: General Package for Meta-Analysis. R package version 4.3-2. Accessed Jun. 17, 2016. https://cran.r-project. org/web/packages/meta/index.html.

Sogstad, A. M., T. Fjeldaas, O. Østerås, and K. P. Forshell. 2005. Prevalence of claw lesions in Norwegian dairy cattle housed in tie stalls and free stalls. Prev. Vet. Med. 70:191-209. https://doi. org $/ 10.1016 /$ j.prevetmed.2005.03.005.

Speijers, M. H. M., L. G. Baird, G. A. Finney, J. McBride, D. J. Kilpatrick, D. N. Logue, and N. E. O'Connell. 2010. Effectiveness of different footbath solutions in the treatment of digital dermatitis in dairy cows. J. Dairy Sci. 93:5782-5791. https://doi.org/10.3168/ jds.2010-3468.

Thomsen, P. T. 2015. Short communication: Efficacy of copper sulfate hoof baths against digital dermatitis - Where is the evidence? J. Dairy Sci. 98:2539-2544. https://doi.org/10.3168/jds.2014-9135.

Thomsen, P. T., J. T. Sørensen, and A. K. Ersbøll. 2008. Evaluation of three commercial hoof-care products used in footbaths in Danish dairy herds. J. Dairy Sci. 91:1361-1365. https://doi.org/10.3168/ jds.2007-0820.

Zinicola, M., H. Higgins, S. Lima, V. Machado, C. Guard, and R. Bicalho. 2015. Shotgun metagenomic sequencing reveals functional genes and microbiome associated with bovine digital dermatitis. PLoS One 10:e0133674. https://doi.org/10.1371/journal. pone. 0133674 